\title{
Therapeutic Potential of Curcumin in Breast Cancer: From Basic Research to Clinical Applications
}

\author{
Milad Hashemzehi, ${ }^{1}$ Soodabeh ShahidSales, ${ }^{2}$ Seyed Mahdi Hassanian, ${ }^{3,4}$ Mona Joudi Mashhad, ${ }^{2}$ Amir \\ Avan, $4,5,{ }^{*}$ and Majid Khazaei ${ }^{1, *}$ \\ ${ }^{1}$ Department of Medical Physiology, Faculty of Medicine, Mashhad University of Medical Sciences, Mashhad, IR Iran \\ ${ }^{2}$ Cancer Research Center, Mashhad University of Medical Sciences, Mashhad, IR Iran \\ ${ }^{3}$ Department of Medical Biochemistry, Faculty of Medicine, Mashhad University of Medical Sciences, Mashhad, IR Iran \\ ${ }^{4}$ Metabolic syndrome Research center, Mashhad University of Medical Sciences, Mashhad, IR Iran \\ ${ }^{5}$ Department of Modern Sciences and Technologies, School of Medicine, Mashhad University of Medical Sciences, Mashhad, IR Iran \\ "Corresponding authors: Amir Avan, Ph.D. Metabolic syndrome Research Center, Mashhad University of Medical Sciences, Mashhad, IR Iran. Tel: +98-51138002298, Fax: \\ +98-5118002287. E-mail: avana@mums.ac.ir; Majid Khazaei, MD, PhD, Department of Physiology, Faculty of Medicine, Mashhad University of Medical Sciences, Mashhad, IR \\ Iran. E-mail: khazaeim@mums.ac.ir
}

Received 2015 September 30; Accepted 2015 November 28.

\begin{abstract}
Breast cancer is among the most common types of cancer and the second leading cause of cancer-related death in women. Therefore, finding treatments with the highest effectiveness and least side effects is of great importance. Curcuma langa, commonly known as curcumin, has many advantages, including antioxidant, antiinflammatory, anticancer, and wound-healing properties. The anticancer mechanisms include prevention of malignant cell formation, as well as reduction of angiogenesis and tumor growth, as documented in some malignancies, including pancreatic, ovarian, gastric, and colorectal cancers. Recent research has also documented curcumin activities against breast cancer, in particular molecular pathways involved in cell growth, differentiation, apoptosis, and suppression of inflammation. Therefore, the aim of the current review was to study the effects of curcumin on breast cancer. Conflicts of Interest: The authors declare no conflicts of interest.
\end{abstract}

Keywords: Curcumin, Breast Cancer, Anticancer Effects

\section{Introduction}

Breast cancer is the most common type of cancer in women ( $22 \%$ of all cancers) and is the second leading cause of cancer-related death, following lung cancer (15\% of all deaths) in this population. In the past 10 - 15 years, timely screening methods, as well as new and effective medications, have helped reduce the mortality rate to $2-3 \%$ (1). Based on previous research, factors such as higher age, geographical location, socioeconomic status, and reproductive status (eg, menarche, menopause, and pregnancy), together with hormonal status, lifestyle (eg, diet, alcohol consumption, obesity, and physical activity), family history, ionizing radiation, and genetic factors, can all contribute to breast cancer (2).

The medications for breast cancer include cyclophosphamide, methotrexate, 5-fluorouracil, doxorubicin, epirubicin, docetaxel, tamoxifen, anastrozole, exemestane, and carboplatin (3). However, it seems necessary to find drugs with greater effectiveness against breast cancer. Turmeric is a spice with a plant origin from the Zingiberaceae family, with the scientific name of Curcuma langa. The Indian traditional medicine (Ayurveda) uses turmeric as a disinfectant to reduce inflammation and promote wound healing (4).

At least 235 compounds have been detected in Curcuma langa, which predominantly include phenols and terpenoids. Among these constituents, curcuminoids are of the greatest importance (5). In fact, curcumin is the most important curcuminoid in turmeric, besides desmethoxycurcumin, bidesmethoxycurcumin, and cyclocurcumin. In general, curcuminoids are polyphenols, responsible for the yellow color of turmeric. Curcumin has 2 tautomeric forms of keto and enol. The enol form is more stable in solid and solute phases (4).

\section{Antioxidant Effects}

Oxygen consumption in growing cells leads to the formation of reactive oxygen species (ROS) (6). ROS also forms in normal body conditions and causes peroxidation of cell membrane lipids through lipid peroxidase accumulation. ROS also has the potential to damage other biomolecules, such as nucleic acids, proteins, and carbohydrates. ROS, if not completely removed from the body, may lead to diseases. Overall, there are around 100 diseases, in which ROS is known to be involved (7). 
Curcumin acts as a substrate for lipoxygenases and an inhibitor of cyclooxygenase (COX) $(8,9)$. Some curcumin activities are dependent on its ability to eliminate oxygen and nitrogen free radicals from the body (10). It has a greater antioxidant capacity, compared to vitamin $\mathrm{C}$ and $\mathrm{E}$. In a study on heart ischemia in cats, a reduction was observed in ischemic changes. Furthermore, in another in vitro study regarding the effects of curcumin on heme oxygenase 1 in bovine aortic endothelial cells, 18 hours of exposure to curcumin increased cellular resistance to oxidative damage (4).

Moreover, in mice with Ehrlich tumors, curcumin inhibited the formation of superoxides and eliminated peroxides and hydroxyl radicals (11). Additionally, in a study on colon cancer cells, ROS production was induced after 15 minutes of curcumin exposure, while 2 hours later, the amount of ROS started to decrease until it reached the normal level; this finding suggests the antioxidant effects of curcumin (12).

\section{Antiinflammatory Effects}

COX plays an important role in the metabolism of arachidonic acids and inflammatory pathways. COX-2 is believed to contribute to the occurrence of colorectal, breast, head and neck, lung, pancreatic, gastric, and prostatic cancers (13). Molecular studies have shown the inhibitory effects of curcumin on agents and enzymes, leading to inflammatory responses. For instance, curcumin could reduce the activity and expression of COX-2 in various cellular and animal studies $(14,15)$. In addition to decreasing COX-2 expression, curcumin could reduce the expression of prostaglandins and prostaglandin E (PGE2) synthase 1 , which are major factors in inflammation and tumor growth (16).

Curcumin reversibly prevents the conversion of prostaglandin $\mathrm{H} 2$ to PGE2 through PGE2 synthase 1 in lung cancer cells via stimulation of interleukin-1 $\beta$ (17). Curcumin prevents the expression of proinflammatory genes through inactivation of activator protein 1 (AP-1) and nuclear factor B (NF-B). AP-1 and NF-B are gene transcription factors, which are expressed in cancer cells and are involved in inflammatory responses caused by lipopolysaccharides (LPS) (16). Moreover, it inhibits the production of proinflammatory cytokine, interleukin-18, with strong inflammatory effects (18).

\section{Anticancer Effects}

According to the literature, curcumin has anticancer effects. These effects include prevention of malignant cell formation, angiogenesis, and tumor growth (4). In lung cancer, curcumin prevents differentiation and angiogenesis (19). By hindering the expression of EGFR and COX-2 genes, curcumin induces apoptosis in lung and pancreatic cancer cells. Moreover, inhibition of EGFR-tyrosine kinase inhibitors (TKIs) reduces lung tumor growth.

The effects of curcumin have been also studied in animal models of lung cancer. These studies have suggested that curcumin increases the anticancer effects of gefitinib, while reducing its gastrointestinal side effects. In a similar study, curcumin, along with erlotinib, restricted the growth of lung tumors. In this regard, an ongoing clinical trial has assessed the effects of a combination of curcumin with gefitinib and erlotinib on 20 cases of lung cancer since 2015. In this research, patients received curcumin with gefitinib and erlotinib, and the effects of curcumin were studied for 8 weeks.

In another ongoing study, the role of curcumin on the salivary glands of chronic obstructive pulmonary disease (COPD) patients is being evaluated. The dose of curcumin used in this study was $1 \mathrm{~g}$ in the first month and $2 \mathrm{~g}$ in the second month (20). Research on pancreatic cancer has also shown the role of curcumin in the reduction of tumor size, prevention of angiogenesis (21), and tumor growth inhibition (22). The effects of curcumin on pancreatic cancer have been demonstrated by orthotopic injection of cancer cells in mice. The results showed that curcumin could inhibit tumor growth by interrupting the NF-kB pathway (23).

Another similar study showed the effect of curcumin on tumor growth inhibition by preventing SP transcription (24). Moreover, in the second phase of a clinical trial on pancreatic cancer, curcumin reduced the expression of NF-kB, COX-2, and phosphorylated signal transducer of transcription 3 in mononuclear blood cells (25). Moreover, Epelbaum et al. evaluated the combined effects of curcumin with gemcitabine in 17 pancreatic cancer patients. The results showed that low-dose curcumin, together with gemcitabine, has therapeutic effects (26).

Another similar study measured the toxic level of curcumin and showed no toxicity at therapeutic doses. Based on the findings, $8 \mathrm{~g} /$ day of curcumin was selected as the acceptable dosage for future studies (27). Recent research concludes that curcumin acts as an iron chelator, which may cause iron-deficiency anemia in those with dietary iron intake (28); curcumin can therefore influence iron metabolism. Moreover, curcumin prescription to rats with hepatoma and ascites results in tumor growth reduction (29).

In prostatic cancer, curcumin induces apoptosis and inhibits cell differentiation (30). A previous study demonstrated that curcumin reduces the number of metastatic 
nodules (31). According to research on ovarian cancer, curcumin inhibits tumor growth, reduces cell differentiation, results in decreased microvasculature, and induces apoptosis in the cells (16). Numerous studies on gastric cancer have shown the inhibitory effect of curcumin on this disease. According to these studies, curcumin increased the lifetime and reduced the number of tumors in the treatment group, compared to the controls (32). In another study on MKN-45 cells, curcumin caused a reduction in weight, prevented cell differentiation, and decreased IL-6 secretion (33).

In the second phase of a clinical study in which colonoscopy and aberrant crypt foci (ACF) count were performed in 44 smokers, curcumin could reduce the number of ACFs in colonic cancer patients (34). Previous studies show that curcumin is not toxic at therapeutic doses, and a daily dose of $2.2 \mathrm{~g}$ can be prescribed in patients with colorectal cancer (35). The maximum acceptable dose of curcumin, used in combination with a standard dose of docetaxel, is $6,000 \mathrm{mg} /$ day for 3 weeks in breast cancer chemotherapy (29). In this regard, Ghalaut et al. confirmed the anticancer role of turmeric powder in 50 chronic myelogenous leukemia (CML) patients. By reducing the amount of nitric oxide in the body, curcumin could act as a therapeutic agent in these patients (36).

\section{Anticancer Effects on Breast Cancer}

$\mathrm{NF}-\mathrm{kB}$ is one of the pathways, which affects the viability, differentiation, and metastasis of breast cancer cells. Curcumin inhibits this pathway by controlling $\operatorname{IkB} \alpha$ and $\operatorname{IkB} \alpha$ kinase, activating IkB $\alpha$ through phosphorylation. The inhibition of NF-kB pathway by curcumin leads to the prevention of antiapoptosis gene expression (eg, IAP1/2, XIAP, Bcl2 , and Bcl-xL) and causes apoptosis in breast cancer cells.

Through inhibition of NF-B pathway, curcumin prevents the expression of genes involved in cell differentiation and metastasis. It also inhibits cyclin D1, c-Myc, COX2, and cellular matrix metalloproteinase-2 (MMP-2) (37). A study on MCF-7 cells confirmed the presence of 214 genes, affecting apoptosis in malignant cells. Based on the findings, curcumin could change the expression of 114 genes. Curcumin concentrations of 25 and $50 \mu \mathrm{g} / \mathrm{mL}$ lead to the increased expression of 22 genes, while reducing the expression of 17 genes. On the other hand, further changes in the expression of other genes are dose-dependent (38).

In addition, curcumin affects the Wnt pathway in MCF7 and MDA-MB-231 cell lines (involved in cell differentiation and oncogenesis). The results showed that in both cell lines, curcumin could inhibit Wnt $/ \beta$-catenin components, including disheveled $\beta$-catenin, cyclinD1, and slug. Treatment with curcumin resulted in changes in the expression of GSK3 $\beta$ and E-cadherin proteins in the Wnt pathway. The changes made by curcumin in this pathway inhibited cell differentiation and induced apoptosis (39).

In a previous study, the effects of curcumin on cell growth and apoptosis were assessed in MBA-MB-231 and MCF-7 cell lines, as well as BALB/c mice, which were subcutaneously injected MBA-MB-231 cells. The results confirmed the inhibitory effects of curcumin on these cell lines. Apoptosis was detected through the expression of Bax apoptotic protein and inhibition of Bcl-2 antiapoptosis protein (increased $\mathrm{Bax} / \mathrm{Bcl} 2$ ratio). Moreover, in vivo, curcumin could reduce the size and volume of tumor, which demonstrates its preventive role against tumor growth (40).

In a study on MCF-7 cells, after 24 hours, curcumin reduced the number of cells in the G0/G1 phase. It also meaningfully reduced the expression of $\mathrm{P} 53$ protein and consequently Bax and Bcl-Xl, resulting in the induction of apoptosis (41). In a similar study on MCF-7 cell line, curcumin reduced cell line differentiation within 6 days. The effects in the first 48 hours maintained the cells in the M phase, prevented DNA synthesis and monopolar mitotic spindles, and eventually inhibited normal chromosomal movement in the anaphase. After 48 hours, the cell passed the $M$ phase; however, instead of 2 daughter nuclei, a large number of small nuclei were formed inside it (42).

One of the reasons for the progression of breast cancer is inflammation (43). A study on curcumin effects on MBA-MB-231 cell line demonstrated the increased expression of hemeoxygenase 1 (HMOX1) and glutamatecysteine ligase modifier (GCLM) genes, despite the lower expression of EGR1, prostaglandin-endoperoxide synthase 2/COX2 (PTGS2/COX2), CXCL1, and CXCL2 chemokines. The expression of genes, related to these cytokines, is controlled by the NFkB pathway (44).

By increasing the expression of some miRNAs, particularly mir81b in metastatic cell lines, curcumin inhibits CXCL1 and CXCL2 and consequently prevents cell differentiation, reduces the aggressive potential, and induces apoptosis (45). Moreover, the effect of curcumin on tumor growth was studied in the MCF-7 cell line. Based on the findings, curcumin inhibited cell differentiation. In addition, the aggressive potential of these cells showed a significant reduction, which could be attributed to the decreased NFkB expression and $\mu$ PA activity (46).

In a similar study, the effects of curcumin on differentiation of MDA-MB-231 and CDK4 cell lines were demonstrated. Response to curcumin included the expression of cyclin D1 in MDA-MB-231 and CDK4 cells, which significantly reduced in BT- 483 cells. In addition, the expression of mRNA, related to MMP1, decreased in both cell lines. These effects of curcumin are mainly attributed to the inhibition of NFkB pathway (47). 
Furthermore, a study examined how curcumin affects mobilization and metastasis in MDA-MB-435 and MDA-MB231 cell lines and assessed the role of $\alpha 6 \beta 4$ integrin as a factor influencing cell mobilization. Curcumin could inhibit the phosphorylation of $\beta 4$ integrin, which is necessary for PI3K activation and cell mobilization. Curcumin also prevented Akt activation and ENPP2 expression, which are also essential to cell mobilization. Based on the findings, cell mobilization and metastasis were prevented by the inhibition of $\alpha 6 \beta 4$ integrins (48).

The results of a study on MDA-MB-231 cell line showed that curcumin inhibits the aggressive effect of transforming growth factor- $\beta 1$ (TGF- $\beta 1$ ) on this cell line. In addition, curcumin negatively affects the synthesis of MMP-9 and activates Smad2, ERK1/2, and p38 through TGF- $\beta 1$. According to the findings, the role of TGF- $\beta 1$ in the stimulation of MMP-9 and aggressive behaviors of malignant cells is dependent on TGF- $\beta /$ SMAD and TGF- $\beta /$ ERK pathways (49).

MMP-9 is one of the main factors contributing to the aggressive behaviors of cancer cells. Curcumin inhibits the expression of 12-o-tetradecanoylphorbol-13-acetate (TPA)dependent MMP-9 in the MCF-7 cell line. This effect of curcumin is applied through the suppression of NFkB and AP-1 pathways, inhibition of P38 and JNK phosphorylation, and prevention of protein kinase $\mathrm{C}$ alpha $(\mathrm{PKC} \alpha)$ transport (50).

Moreover, curcumin influences the activity of telomerase enzymes. In studies on T47D cell line, the inhibitory effects of curcumin on the expression of hTERT gene, followed by inhibition of telomerase enzymes, resulted in growth inhibition in the cell line (51). The results of another study on the MCD-7 cell line showed that telomerase activity reduced in the presence of curcumin. This finding might be related to the decreased expression of hTERT gene, while hTER expression was not affected (52).

One of the enzymes, which has been recently discovered to be involved in the growth and differentiation of cancer cells, is Flap endonuclease 1(Fen1). Curcumin causes an increase in the expression of Nrf2 proteins in the MCF7 cell line, thereby stimulating its transfer from the cytoplasm into the nucleus and inhibiting Fen1 and consequently cell growth and differentiation (53).

\section{Conclusions}

Considering the anticancer properties of curcumin, as confirmed in many studies, and its nontoxic therapeutic doses, turmeric and its effective ingredients, particularly curcumin, may be suitable adjuvant cancer treatments, used with other standard medications. Future studies can indeed expand the current knowledge on breast cancer, while clinical studies can improve our understanding about the therapeutic effects of curcumin. On the other hand, since curcumin has a low absorption rate and bioavailability, other forms with higher levels of bioavailability, such as Theracurmin, are recommended.

\section{References}

1. Stewart SL, King JB, Thompson TD, Friedman C, Wingo PA. Cancer mortality surveillance-United States, 1990-2000. MMWR Surveill Summ. 2004;53(3):1-108. [PubMed: 15179359].

2. Dumitrescu RG, Cotarla I. Understanding breast cancer risk - where do we stand in 2005? J Cell Mol Med. 2005;9(1):208-21. [PubMed: 15784178].

3. Montazeri A. Health-related quality of life in breast cancer patients: a bibliographic review of the literature from 1974 to 2007.J Exp Clin Cancer Res. 2008;27:32. doi: 10.1186/1756-9966-27-32. [PubMed:18759983].

4. Akram M, Uddin S, Ahmed A, Usmanghani K, Hannan A, Mohiuddin E, et al. Curcuma longa and curcumin: a review article. Rom J Biol Plant Biol. 2010;55(2):65-70.

5. Li S, Yuan W, Deng G, Wang P, Yang P, Aggarwal BB. Chemical composition and product quality control of turmeric (Curcuma longa L.). 2011.

6. Barros L, Ferreira MJ, Queiros B, Ferreira ICFR, Baptista P. Total phenols, ascorbic acid, $\beta$-carotene and lycopene in Portuguese wild edible mushrooms and their antioxidant activities. Food Chem. 2007;103(2):413-9. doi: 10.1016/j.foodchem.2006.07.038.

7. Halliwell B, Gutteridge JM. Role of free radicals and catalytic metal ions in human disease: an overview. Methods Enzymol. 1990;186:1-85. [PubMed: 2172697].

8. Huang MT, Lysz T, Ferraro T, Abidi TF, Laskin JD, Conney AH. Inhibitory effects of curcumin on in vitro lipoxygenase and cyclooxygenase activities in mouse epidermis. Cancer Res. 1991;51(3):813-9. [PubMed: 1899046].

9. Skrzypczak-Jankun E, McCabe NP, Selman SH, Jankun J. Curcumin inhibits lipoxygenase by binding to its central cavity: theoretical and X-ray evidence. Int J Mol Med. 2000;6(5):521-6. [PubMed: 11029517].

10. Priyadarsini KI, Maity DK, Naik GH, Kumar MS, Unnikrishnan MK, Satav JG, et al. Role of phenolic O-H and methylene hydrogen on the free radical reactions and antioxidant activity of curcumin. Free Radic Biol Med. 2003;35(5):475-84. [PubMed:12927597].

11. Ruby AJ, Kuttan G, Babu KD, Rajasekharan KN, Kuttan R. Antitumour and antioxidant activity of natural curcuminoids. Cancer Lett. 1995;94(1):79-83. [PubMed: 7621448].

12. Su CC, Lin JG, Li TM, Chung JG, Yang JS, Ip SW, et al. Curcumin-induced apoptosis of human colon cancer colo 205 cells through the production of ROS, Ca2+ and the activation of caspase-3. Anticancer Res. 2006;26(6B):4379-89. [PubMed: 17201158].

13. Sharma RA. Translational medicine: targetting cyclo-oxygenase isozymes to prevent cancer. QJM. 2002;95(5):267-73. [PubMed: 11978897].

14. Surh YJ, Chun KS. Cancer chemopreventive effects of curcumin. Adv Exp Med Biol. 2007;595:149-72. doi: 10.1007/978-0-387-46401-5_5. [PubMed: 17569209].

15. Surh YJ, Chun KS, Cha HH, Han SS, Keum YS, Park KK, et al. Molecular mechanisms underlying chemopreventive activities of antiinflammatory phytochemicals: down-regulation of COX-2 and iNOS through suppression of NF-kappa B activation. Mutat Res. 2001;480481:243-68. [PubMed: 11506818].

16. Perrone D, Ardito F, Giannatempo G, Dioguardi M, Troiano G, Lo Russo L, et al. Biological and therapeutic activities, and anticancer properties of curcumin. Exp Ther Med. 2015;10(5):1615-23. doi: 10.3892/etm.2015.2749. [PubMed: 26640527]. 
17. Li Y, Zhang S, Geng JX, Hu XY. Curcumin inhibits human non-small cell lung cancer A549 cell proliferation through regulation of Bcl2/Bax and cytochrome C. Asian Pac J Cancer Prev. 2013;14(8):4599-602. [PubMed: 24083709].

18. Yadav R, Jee B, Awasthi SK. Curcumin Suppresses the Production of Pro-inflammatory Cytokine Interleukin-18 in Lipopolysaccharide Stimulated Murine Macrophage-Like Cells. Indian J Clin Biochem. 2015;30(1):109-12. doi:10.1007/s12291-014-0452-2. [PubMed: 25646051].

19. Yang CL, Liu YY, Ma YG, Xue YX, Liu DG, Ren Y, et al. Curcumin blocks small cell lung cancer cells migration, invasion, angiogenesis, cell cycle and neoplasia through Janus kinase-STAT3 signalling pathway. PLoS One. 2012;7(5):e37960. doi: 10.1371/journal.pone.0037960. [PubMed: 22662257].

20. Shafiee M, Mohamadzade E, ShahidSales S, Khakpouri S, Maftouh M, Parizadeh SA, et al. Current Status and Perspectives Regarding the Therapeutic Potential of Targeting EGFR Pathway by Curcumin in Lung Cancer. Curr Pharm Des. 2017;23(13):2002-8. doi: 10.2174/1381612823666170123143648. [PubMed: 28117012].

21. Li L, Braiteh FS, Kurzrock R. Liposome-encapsulated curcumin: in vitro and in vivo effects on proliferation, apoptosis, signaling, and angiogenesis. Cancer. 2005;104(6):1322-31. doi: 10.1002/cncr.21300. [PubMed: 16092118]

22. Bao B, Ali S, Banerjee S, Wang Z, Logna F, Azmi AS, et al. Curcumin analogue CDF inhibits pancreatic tumor growth by switching on suppressor microRNAs and attenuating EZH2 expression. Cancer Res. 2012;72(1):335-45. doi: 10.1158/0008-5472.CAN-11-2182. [PubMed: 22108826].

23. Bimonte S, Barbieri A, Palma G, Luciano A, Rea D, Arra C. Curcumin inhibits tumor growth and angiogenesis in an orthotopic mouse model of human pancreatic cancer. BioMed Res Int. 2013;2013.

24. Jutooru I, Chadalapaka G, Lei P, Safe S. Inhibition of NFkappaB and pancreatic cancer cell and tumor growth by curcumin is dependent on specificity protein down-regulation. J Biol Chem. 2010;285(33):25332-44. doi: 10.1074/jbc.M109.095240. [PubMed: 20538607].

25. Dhillon N, Aggarwal BB, Newman RA, Wolff RA, Kunnumakkara AB, Abbruzzese JL, et al. Phase II trial of curcumin in patients with advanced pancreatic cancer. Clin Cancer Res. 2008;14(14):4491-9.

26. Epelbaum R, Schaffer M, Vizel B, Badmaev V, Bar-Sela G. Curcumin and gemcitabine in patients with advanced pancreatic cancer. Nutr Cancer. 2010;62(8):1137-41. doi: 10.1080/01635581.2010.513802. [PubMed: 21058202]

27. Kanai M, Yoshimura K, Asada M, Imaizumi A, Suzuki C, Matsumoto $S$, et al. A phase I/II study of gemcitabine-based chemotherapy plus curcumin for patients with gemcitabine-resistant pancreatic cancer. Cancer Chemother Pharmacol. 2011;68(1):157-64. doi: 10.1007/s00280010-1470-2. [PubMed: 20859741].

28. Phase I . Clinical Trial of Oral Curcumin: Biomarkers of Systemic Activity and Compliance Sharma. Ricky A; 2010.

29. Hosseini M, Hassanian SM, Mohammadzadeh E, ShahidSales S, Maftouh M, Fayazbakhsh $\mathrm{H}$, et al. Therapeutic Potential of Curcumin in Treatment of Pancreatic Cancer: Current Status and Future Perspectives. J Cell Biochem. 2017;118(7):1634-8. doi: 10.1002/jcb.25897. [PubMed: 28106283].

30. Dorai T, Cao YC, Dorai B, Buttyan R, Katz AE. Therapeutic potential of curcumin in human prostate cancer. III. Curcumin inhibits proliferation, induces apoptosis, and inhibits angiogenesis of LNCaP prostate cancer cells in vivo. Prostate. 2001;47(4):293-303. doi: 10.1002/pros.1074. [PubMed: 11398177].

31. Hong JH, Ahn KS, Bae E, Jeon SS, Choi HY. The effects of curcumin on the invasiveness of prostate cancer in vitro and in vivo. Prostate Cancer Prostatic Dis. 2006;9(2):147-52. doi: 10.1038/sj.pcan.4500856. [PubMed: 16389264].

32. Cui SX, Qu XI, Xie YY, Zhou L, Nakata M, Makuuchi M, et al. Curcumin inhibits telomerase activity in human cancer cell lines. Int J Mol Med. 2006;18(2):227-31. [PubMed: 16820928].
33. Tu SP, Jin H, Shi JD, Zhu LM, Suo Y, Lu G, et al. Curcumin induces the differentiation of myeloid-derived suppressor cells and inhibits their interaction with cancer cells and related tumor growth. Cancer Prev Res (Phila). 2012;5(2):205-15. doi: 10.1158/1940-6207.CAPR-11-0247. [PubMed: 22030090].

34. Carroll RE, Benya RV, Turgeon DK, Vareed S, Neuman M, Rodriguez L, et al. Phase IIa clinical trial of curcumin for the prevention of colorectal neoplasia. Cancer Prev Res (Phila). 2011;4(3):354-64. doi: 10.1158/19406207.CAPR-10-0098. [PubMed: 21372035].

35. Sharma RA, McLelland HR, Hill KA, Ireson CR, Euden SA, Manson MM, et al. Pharmacodynamic and pharmacokinetic study of oral Curcuma extract in patients with colorectal cancer. Clin Cancer Res. 2001;7(7):1894-900. [PubMed: 11448902].

36. Ghalaut VS, Sangwan L, Dahiya K, Ghalaut PS, Dhankhar R, Saharan R. Effect of imatinib therapy with and without turmeric powder on nitric oxide levels in chronic myeloid leukemia. J Oncol Pharm Pract. 2012;18(2):186-90. doi: 10.1177/1078155211416530. [PubMed: 21844132].

37. Aggarwal BB, Shishodia S, Takada Y, Banerjee S, Newman RA, BuesoRamos CE, et al. Curcumin suppresses the paclitaxel-induced nuclear factor-kappaB pathway in breast cancer cells and inhibits lung metastasis of human breast cancer in nude mice. Clin Cancer Res. 2005;11(20):7490-8. doi: 10.1158/1078-0432.CCR-05-1192. [PubMed: 16243823].

38. Ramachandran C, Rodriguez S, Ramachandran R, Raveendran Nair PK, Fonseca H, Khatib Z, et al. Expression profiles of apoptotic genes induced by curcumin in human breast cancer and mammary epithelial cell lines. Anticancer Res. 2005;25(5):3293-302. [PubMed: 16101141].

39. Prasad CP, Rath G, Mathur S, Bhatnagar D, Ralhan R. Potent growth suppressive activity of curcumin in human breast cancer cells: Modulation of Wnt/beta-catenin signaling. Chem Biol Interact. 2009;181(2):263-71. doi: 10.1016/j.cbi.2009.06.012. [PubMed: 19573523].

40. Lv ZD, Liu XP, Zhao WJ, Dong Q, Li FN, Wang HB, et al. Curcumin induces apoptosis in breast cancer cells and inhibits tumor growth in vitro and in vivo. Int J Clin Exp Pathol. 2014;7(6):2818-24. [PubMed: 25031701].

41. Choudhuri T, Pal S, Agwarwal ML, Das T, Sa G. Curcumin induces apoptosis in human breast cancer cells through p53-dependent Bax induction. FEBS Lett. 2002;512(1-3):334-40. [PubMed:11852106].

42. Holy JM. Curcumin disrupts mitotic spindle structure and induces micronucleation in MCF-7 breast cancer cells. Mutat Res. 2002;518(1):71-84. [PubMed: 12063069].

43. DeNardo DG, Coussens LM. Inflammation and breast cancer. Balancing immune response: crosstalk between adaptive and innate immune cells during breast cancer progression. Breast Cancer Res. 2007;9(4):212. doi: 10.1186/bcr1746. [PubMed:17705880].

44. Bachmeier BE, Mohrenz IV, Mirisola V, Schleicher E, Romeo F, Hohneke C, et al. Curcumin downregulates the inflammatory cytokines CXCL1 and -2 in breast cancer cells via NFkappaB. Carcinogenesis. 2008;29(4):779-89. doi: 10.1093/carcin/bgm248. [PubMed: 17999991].

45. Kronski E, Fiori ME, Barbieri O, Astigiano S, Mirisola V, Killian PH, et al. miR181b is induced by the chemopreventive polyphenol curcumin and inhibits breast cancer metastasis via down-regulation of the inflammatory cytokines CXCL1 and -2. Mol Oncol. 2014;8(3):581-95. doi: 10.1016/j.molonc.2014.01.005. [PubMed: 24484937].

46. Zong H, Wang F, Fan QX, Wang LX. Curcumin inhibits metastatic progression of breast cancer cell through suppression of urokinasetype plasminogen activator by NF-kappa B signaling pathways. Mol Biol Rep. 2012;39(4):4803-8. doi: 10.1007/s11033-011-1273-5. [PubMed: 21947854].

47. Liu Q, Loo WT, Sze SC, Tong Y. Curcumin inhibits cell proliferation of MDA-MB-231 and BT-483 breast cancer cells mediated by down-regulation of NFkappaB, cyclinD and MMP-1 transcription. Phytomedicine. 2009;16(10):916-22. doi: 10.1016/j.phymed.2009.04.008. [PubMed: 19524420]. 
48. Kim HI, Huang H, Cheepala S, Huang S, Chung J. Curcumin inhibition of integrin (alpha6beta4)-dependent breast cancer cell motility and invasion. Cancer Prev Res (Phila). 2008;1(5):385-91. doi: 10.1158/19406207.CAPR-08-0087. [PubMed: 19138983].

49. Mo N, Li ZQ, Li J, Cao YD. Curcumin inhibits TGF-beta1-induced MMP9 and invasion through ERK and Smad signaling in breast cancer MDA-MB-231 cells. Asian Pac JCancerPrev. 2012;13(11):5709-14. [PubMed: 23317243].

50. Kim JM, Noh EM, Kwon KB, Kim JS, You YO, Hwang JK, et al Curcumin suppresses the TPA-induced invasion through inhibition of PKCalpha-dependent MMP-expression in MCF-7 human breast cancer cells. Phytomedicine. 2012;19(12):1085-92. doi: 10.1016/j.phymed.2012.07.002. [PubMed: 22921746].
51. Nasiri M, Zarghami N, Koshki KN, Mollazadeh M, Moghaddam MP Yamchi MR, et al. Curcumin and silibinin inhibit telomerase expression in T47D human breast cancer cells. Asian Pac J Cancer Prev 2013;14(6):3449-53. [PubMed: 23886126].

52. Ramachandran C, Fonseca HB, Jhabvala P, Escalon EA, Melnick SJ. Curcumin inhibits telomerase activity through human telomerase reverse transcritpase in MCF-7 breast cancer cell line. Cancer Lett. 2002;184(1):1-6. [PubMed: 12104041].

53. Chen B, Zhang Y, Wang Y, Rao J, Jiang X, Xu Z. Curcumin inhibits proliferation of breast cancer cells through Nrf2-mediated downregulation of Fen1 expression. J Steroid Biochem Mol Biol. 2014;143:11-8. doi: 10.1016/j.jsbmb.2014.01.009. [PubMed: 24486718]. 